
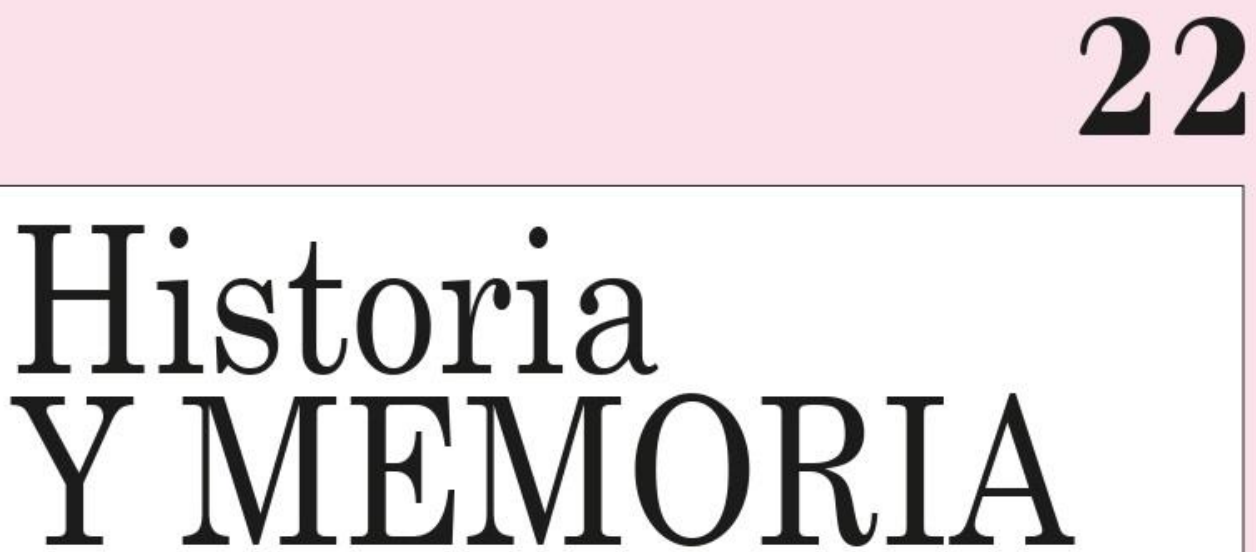

ISSN: 2027-5137

Enero - Junio, Año 2021 - Tunja, Colombia

El fin de la era de los grandes editores de prensa y la emergencia de los nuevos modelos digitales. La reconversión del negocio de la información en España en las dos primeras décadas del siglo XXI

https:/doi.org/10.19053/20275137.n22.2021.11138

Juan Carlos Sánchez Illán

Cesar Luena López

Páginas 119-160

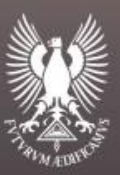




\title{
El fin de la era de los grandes editores de prensa y la emergencia de los nuevos modelos digitales. La reconversión del negocio de la información en España en las dos primeras décadas del siglo XXI*
}

\author{
Juan Carlos Sánchez Illán ${ }^{1}$ \\ César Luena López ${ }^{2}$ \\ Universidad Carlos III de Madrid-España
}

Recepción: 04/06/2020

Evaluación: 03/08/2020

Aprobación: 04/09/2020

Artículo de Investigación e Innovación

https:/doi.org/10.19053/20275137.n22.2021.11138

\section{Resumen}

Durante el sigloXX la prevalencia de grandes editores, con unos perfiles políticos y empresariales muy acusados, como Nicolás María de Urgoiti, Luis Montiel Balanzat y Ángel Herrera Oria, así como de auténticas dinastías periodísticas, presidieron el panorama editorial e ideológico de la prensa española de una

\footnotetext{
* Este trabajo forma parte de los resultados del Proyecto de la Universidad Carlos III de Madrid Historia, Memoria y Sociedad Digital. Nuevas formas de transmisión del pasado. La transición política a la democracia. Programa Retos del Conocimiento, financiado por el Ministerio de Ciencia, Investigación y Universidades y el Fondo Europeo de Desarrollo Regional (FEDER) con referencia RTI2018-093599-B-I00 MCIU/AE/FEDER, UE.

1 profesor titular, acreditado catedrático, Departamento de Comunicación, Universidad Carlos III de Madrid. Autor y director de obras como Diccionario Biográfico del Exilio Español de 1939: los Periodistas; Una República de Papel. L'Espagne Républicaine, 1945-1949; La nación inacabada. Los intelectuales y el proceso de construcción nacional y Prensa y Política en la España de la Restauración. $\triangle$ jcsanche@hum.uc3m.es () https://orcid.org/0000-0002-5692-8022.

2 profesor asociado, Departamento de Ciencias Sociales, Universidad Carlos III de Madrid y eurodiputado. Autor y director de obras como En defensa de Julian Besteiro, socialista; Cien años de la huelga de 1917 y Partidos políticos, democracia y cambio social. $\bowtie$ cluena@hum.uc3m.es (1) https://orcid.org/0000-0003-0644-4887.
} 
forma relativamente nítida. La muerte en 2007 del que puede ser considerado el último de los grandes editores clásicos, Jesús de Polanco, marcó, en buena medida, el final de una era en la edición española, conocida globalmente como la de los grandes magnates de la comunicación periodística.

En las dos primeras décadas del siglo XXI se ha asistido a la aparición de nuevos promotores de prensa, orientados a la edición de medios nacidos en el ecosistema digital. En este trabajo se aborda este cambio de paradigma editorial por medio de entrevistas y con métodos de análisis esencialmente cualitativos. Para ello, se sigue como filosofía de base la propuesta orteguiana del análisis vital de la trayectoria de los protagonistas y de sus medios periodísticos dentro de su circunstancia histórica, como fundamental elemento explicativo.

Palabras clave: periodismo, crisis, modelo de negocio, comunicación periodística, periodismo digital.

\section{The end of the era of the big newspaper publishers and the emergence of the new digital models. The restructuring of the business of information in Spain in the first two decades of the 21 st century.}

\section{Abstract}

During the 20th century, the prevalence of well-known publishers, with substantial political and business profiles, such as Nicolás María de Urgoiti, Luis Montiel Balanzat, and Ángel Herrera Oria, as the authentic journalistic dynasties, presided over the editorial and ideological landscape of the Spanish press in a relatively clear way. The death, in 2007, of what can be considered the last of the great classical publishers, Jesús de Polanco, marked, to a large degree, the end of an era in Spanish publishing, recognized globally as that of the great magnates of journalistic communication.

In the two first decades of the 21st century, the emergence of new patrons of the press has been witnessed, 
oriented towards the editing of media which came into being in the digital environment. In this work, this change of the editorial paradigm is explored through interviews and with methods of analysis that are essentially qualitative. For this, the underlying philosophy will be the proposal of Ortega of the vital analysis of the trajectory of the protagonists and their journalistic media within the historical circumstances, as a fundamental explanatory element.

Key words: journalism, crisis, business model, journalistic communication, digital journalism.

La fin de l'ère des grands éditeurs de presse et

l'émérgence des nouveaux modèles digitaux. La reconversion du marché de l'information en Espagne au début du XXI ${ }^{\mathrm{e}}$ siècle

\section{Résumé}

Au cours du XXe, l'importance des grands éditeurs, avec des tendances politiques et entrepreneuriales très prononcées (tels que Nicolás María de Ugoiti, Luis Montiel Balanzat y Ángel Herrera Oria), ainsi que l'existence de dynasties journalistiques, ont sans doute marqué l'horizon éditorial et idéologique de la presse espagnole de l'époque. La disparition, en 2007, de celui que l'on considère le dernier des grands éditeurs classiques, Jesús de Polanco, a représenté la fin d'une ère de l'édition espagnole, connue globalement pour les milliardaires de la communication journalistique.

$\mathrm{Au}$ début du XXI ${ }^{\mathrm{e}}$ siècle, les promoteurs de presse sont apparus et se sont orientés vers l'écosystème digital. Cet article analyse ce changement de paradigme éditorial à partir d'entretiens et d'autres méthodes d'analyse qualitatifs. Pour ce faire, on suit ce qu'Ortega y Gasset appelait une analyse vitale de la trajectoire des protagonistes et de ses médias journalistiques dans le cadre d'une circonstance historique.

Mots-clés: journalisme, crise, modèle d'activité économique, journalisme digital. 


\section{Introducción. Los grandes editores del siglo XX. Jesús de Polanco, el último magnate de la prensa}

En las dos primeras décadas del siglo $\mathrm{XX}$ se produjo un severo proceso de reajustes y concentración empresarial en el panorama de la prensa española. Una serie de emprendedores y editores, con unas estrategias y líneas editoriales e ideológicas muy definidas, supieron crear nuevas iniciativas periodísticas de largo recorrido. El lector sabía perfectamente lo que se podía encontrar si abría las páginas de estos medios. Esto explica el éxito de sociedades anónimas tan potentes como las promovidas por Torcuato Luca de Tena y Álvarez Ossorio, con $A B C$ (1905) y Prensa Española (1910); de Ángel Herrera Oria, con El Debate (1910-1936) y la Editorial Católica (1913); o de Nicolás María de Urgoiti, con El Sol (19171939) y la creación de Prensa Gráfica (1913-1939), matriz del primer grupo multimedia avant la lettre en la historia del periodismo español ${ }^{3}$. Habían encontrado una fórmula periodística equilibrada. Lo que ahora se llamaría un modelo de negocio, esto es, una combinación acertada de elementos empresariales e ideológicos que lograron inscribirse en un ecosistema adecuado, en el que encontraron un suficiente nicho de mercado para su desarrollo y consolidación.

La prensa, mientras tanto, se industrializaba a pasos agigantados, hace ahora cien años, en la tercera década del siglo XX. Los hermanos Busquets protagonizan la fundación de la Sociedad Editorial Universal, mediante el traspaso, a fines de noviembre de 1922, de los decimonónicos Heraldo de Madrid y El Liberal a una nueva empresa, constituida a tal fin, la Sociedad Editora Universal. Una empresa propiedad de los referidos industriales químicos catalanes, hermanos Manuel y Joan Busquets George, delegados y asociados para España de la todopoderosa Standard Oil de Rockefeller y grandes acreedores de lo que quedaba del Trust o Sociedad Editorial de España, por la provisión de derivados del petróleo, especialmente de las tintas. El trasfondo editorial de la nueva

3 Juan Carlos Sánchez Illán, «La edición de periódicos y la empresa periodística,» en Historia de la edición en España (1836-1936), ed. Jesús Martínez (Madrid: Marcial Pons, 2001), 397-414. 
empresa, nacida con el acrónimo de SEU -Sede en catalánque sería presidida efectivamente, a través de su consejo de administración, por Manuel Busquets George (1872-1955) era un ambicioso proyecto empresarial e intelectual diseñado por su apoderado en la operación, el prestigioso abogado, decano del colegio de abogados de Barcelona y periodista Amadeu Hurtado Miró (1875-1950), de establecer -literalmente- la Sede del catalanismo político y periodístico en Madrid. De la SEDE-Sociedad Editorial de España se pasó a la SEUSociedad Editora Universal. De la sede castellana a la seu catalana, puesto que -en sus propias palabras- "no se trata de ir a hacer catalanismo a Madrid como si estuviéramos en Barcelona, sino de intervenir en la vida española pensando en catalán» ${ }^{4}$.

Sin duda, otro de los grandes protagonistas de este proceso de rápida modernización fue el empresario madrileño Luis Montiel y Balanzat (1884-1976). La semblanza biográfica de este gran personaje del mundo de las artes gráficas $\mathrm{y}$ del periodismo, creador y organizador de numerosas publicaciones antes y después de la Guerra -y mucho menos conocida que la de Nicolás María de Urgoiti-, muestra un perfil formativo y profesional muy alejado de la vieja prensa. Desde el 2 de agosto de 1919 será el flamante propietario de los monumentales Talleres Tipográficos Sucesores de Rivadeneyra, sin duda la industria editorial más potente de la capital del Estado ${ }^{5}$. Montiel, tras adquirir y refundar el ya envejecido establecimiento, se había convertido en uno de los más destacados impulsores en España de la prensa de masas en el primer tercio del siglo XX. Con este importante capital acumulado, se lanzó a poner en marcha, tras una minuciosa prospectiva de mercado, dos exitosas publicaciones, la revista

4 Gil Toll, Heraldo de Madrid, tinta catalana para la II República española (Sevilla: Renacimiento, 2013), 74-76.

5 Datos provenientes de su necrológica, firmada por Agencia Europa Press, La Vanguardia, 17 de julio de 1976; y Agencia Cifra-EFE, $A B C, 17$ de julio de 1976; y entrevista en Madrid a su nieto y actual propietario de Rivadeneyra, Vicente Montiel Armada (Presidente de Sucesores de Rivadeneyra), entrevista por Juan Carlos Sánchez Illán y César Luena López, 12 de mayo de 2020. La compra de los Talleres de Rivadeneyra se formalizó el 2 de agosto de 1919, en Madrid, ante el notario José María de la Torre Izquierdo. 
de información general Estampa y el diario gráfico Ahora, dos de los medios periodísticos más leídos durante los años republicanos, en sus respectivos segmentos editoriales, tanto por su excelente calidad técnica, información y reportajes ágiles como por su línea editorial equilibrada y contar con la subdirección del aclamado periodista Manuel Chaves Nogales ${ }^{6}$.

La profunda y dramática crisis de convivencia de los años 30, la ausencia de legitimidad de los frágiles gobiernos, provocada por la no aceptación del rival político, que redundaría en la definitiva bancarrota del débil Estado liberal español, tiene sus efectos inmediatos en el ejercicio del Periodismo y en la actividad de la Prensa española, truncando el proceso de desarrollo y modernización empresarial iniciado a comienzos de siglo ${ }^{7}$. El éxito de Luis Montiel continuó, sin embargo, en el exilio, concretamente en Argentina, donde reeditó la revista Estampa hasta 1959. Su regreso definitivo, ese año, a España, con el relanzamiento de la revista Semana y del diario deportivo $A s^{8}$ supondrán, en buena medida, una especie de transición y relativa continuidad, mutatis mutandis, entre el periodismo anterior a la Guerra. Así, en 1964 adquirió la totalidad de la sociedad editora Semana S.L., dando un gran impulso al semanario Semana. En 1967 lanzó el diario As, y en 1971, el semanario As-Color. El 12 de julio de 1996 el diario El País publicó que el Grupo PRISA había comprado el 75\% del diario As, la publicación más exitosa de la familia Montiel, con el titular de que «un nuevo equipo se unirá al del periódico deportivo para relanzar la publicación».

\footnotetext{
6 Jesús de Juana López, La posición centrista durante la Segunda República: (el periódico 'Ahora', 1930-1936) (Santiago de Compostela: Servicio de Publicaciones de la Universidad, 1988, passim).

7 Juan Carlos Sánchez Illán, «Los espacios del poder político y periodístico en la Edad de Oro del periodismo español,» en La sociedad urbana en el Madrid contemporáneo, eds. Jesús Martínez y Luis Enrique Otero (Madrid: Libros de la Catarata, 2018), 89-102.

8 Montiel recupera esta cabecera que previamente había editado como revista semanal deportiva desde junio de 1932 a julio de 1936, a través de la empresa de la que había sido propietario, Editorial Estampa.
} 
La figura del empresario cántabro Jesús de Polanco (1929-2007) tomaba así el relevo, simbólico y efectivo, en buena medida, de Luis Montiel, como el último magnate de la prensa histórica. Polanco fue, sin duda, el editor que marcó, con sus iniciativas, la evolución periodística de las tres últimas décadas del siglo $\mathrm{XX}$, en su calidad de empresario de medios más innovador. Primero, como consejero delegado y, desde 1981, en su calidad de propietario de El País y del Grupo PRISA, fue el más destacado empresario editorial formado a partir del desarrollismo franquista de los años 60. Mantuvo contacto con casi todos los políticos de su tiempo, los antiguos franquistas y también los nuevos actores de la Transición. Nunca ocupó un cargo político, pero se convirtió en Jesús del Gran Poder, un epíteto que más tarde sería utilizado en su contra por aquellos que lo acusaron de construir su imperio mediático gracias a los favores políticos y luego poner al servicio de los que lo habían hecho posible. Aunque no escatimó esfuerzos en influir en los cambios que ocurrieron en la regulación del mercado multimedia, su enorme influencia política y económica se derivaría de su capacidad de convertir a la prensa, la radio y la televisión en un gran negocio de la información y la influencia política y empresarial. Desde 1996, precisamente, sus medios de comunicación se embarcaron en una dura guerra política frente al Gobierno de José María Aznar, muy activo en la regulación de la competencia empresarial en el sector de las comunicaciones; un mercado, como es bien sabido, especialmente sensible a las decisiones de los poderes políticos y económicos ${ }^{9}$.

La trayectoria de Polanco es icónica para explicar lo que supuso la integración vertical en grupos de medios. Fue el primero en comprender que el futuro del negocio estaba en la creación de conglomerados multimedia, proceso impulsado, efectivamente, a partir de un negocio consolidado, la Cadena Ser y de uno emergente, Canal Plus. Su muerte, en julio de 2007, supuso el fin de la era de los grandes editores de los

9 Mercedes Cabrera, «Jesús de Polanco and the Prisa Group,» Journal of Evolutionary Studies in Business Vol. 3, $\mathrm{n}^{\circ} 1$ (2018): 278; y, sobre todo, de la misma autora, su monumental biografía Jesús de Polanco, capitán de empresas (Barcelona: Galaxia Gutenberg, 2015, passim). 
medios de comunicación, al menos en España. Casi en paralelo, se asistió a la caída relativa del casi ubicuo imperio editorial de Rupert Murdoch. Los legisladores británicos declararon que no era apto para dirigir una importante empresa internacional. ¿Marca esto el fin del todopoderoso magnate de los medios de comunicación en una sociedad democrática? Después de meses de luchar contra las acusaciones de la actividad ilegal, quedaron atrás los días en que Murdoch podía entrar y salir por la puerta trasera de la residencia del primer ministro en Downing Street ${ }^{10}$. La idea del todopoderoso magnate de los medios de comunicación, con los mismos niveles de influencia tanto en la política como en otras áreas de la vida pública, parecía desaparecer con su figura; sin embargo, hay que recordar que las familias o dinastías que construyen grupos multimedia no fabrican productos convencionales. Se identifican altamente con el conglomerado multimedia que crean y se les otorga, por ello, una especie de estatus privilegiado en la esfera pública.

En el mundo anglosajón se empleó el término mogul para referirse a los titanes de los medios de comunicación y ese estatus es lo suficientemente poderoso, al menos cuando los negocios son prósperos, como para legarse a la próxima generación. Pero, cabe preguntarse si, realmente, se está asistiendo en España al fin de la era de los influyentes y todopoderosos propietarios privados de medios, que con su ideología e iniciativas marcaban el pulso y el devenir de la historia del periodismo, al menos de acuerdo a su modelo occidental.

La hipótesis sobre la que se sustenta este artículo parte del presupuesto de que el cambio del modelo editorial español, del periódico en papel al diario digital, se ha fundamentado en dos causas principales y en un factor de precipitación y aceleración. De un lado, se abordan y explican las causas del desarrollo tecnológico (la principal) y del cambio en las pautas de consumo ligado al relevo generacional (causa secundaria),

10 Véase: Howard R. Gold, «It's the End of the Media Moguls Era», The Wall Street Journal, Nueva York, 18 de agosto de 2005, https://www.wsj.com/articles/ SB112436847596016582. 
como el origen del proceso de evolución del modelo editorial español; y del otro, se constata y desarrolla el impacto de la crisis económica y posterior recesión como gran motor de la transformación del panorama editorial, así como de la rapidez en la concreción de dicho fenómeno histórico. Para corroborar o refutar esta hipótesis se ha consultado a periodistas, profesionales, académicos, políticos y empresarios, cuyas versiones han permitido identificar que los cambios más recientes en el panorama mediático han seguido una lógica esencialmente económica y han obedecido, sobre todo, a una dinámica de naturaleza empresarial, fuertemente condicionada por un contexto de permanente crisis financiera y acelerada revolución tecnológica.

El medio periodístico que ha experimentado un cambio más sensible y palpable en su evolución inmediata ha sido el diario El País. Aunque sigue siendo el que ocupa el liderazgo, en la difusión de sus ediciones en papel y digital, su histórica línea editorial se ha visto severamente afectada y ha atravesado relativos vaivenes en la última década, debido a los efectos combinados de la omnipresente crisis económica. Se trata, de hecho, de un medio que se encuentra, en la actualidad, en manos de sus acreedores financieros, en situación de bancarrota técnica y que, quizá por todo ello, ahora se decanta cada vez más claramente por el olvido y la equidistancia en el tratamiento ideológico, de los asuntos más delicados de la historia española del siglo XX, dejando el asunto exclusivamente en manos de los historiadores profesionales: sin embargo, el nombramiento -en junio de 2018- de una directora, por primera vez en su historia, la veterana redactora -prácticamente en plantilla desde sus inicios, en mayo de 1976- Soledad Gallego Díaz, ha supuesto un retorno del buque insignia de la empresa a los años dorados, por su rentabilidad económica e influencia política y cultural, como indiscutida referencia dominante, de la Transición y de los años 80. Dos años después, el 15 de junio de 2020, su relevo por quien ya había sido director en una etapa anterior (2006-2014), Javier Moreno Barber, vuelve a poner en un marco de gran incertidumbre tanto su recorrido editorial y posicionamiento ideológico como su política comercial. 
En este panorama de análisis tan complejo, tres han sido los principales interrogantes que han servido para guiar teóricamente esta investigación. De hecho, constituyen los tres ejes que vertebran el análisis y el enfoque teórico del trabajo. A saber, cuáles han sido las principales causas de la evolución y transformación del conglomerado editorial español, qué factores y tendencias aceleraron esa dinámica de cambio en los primeros años del siglo XXI y, por último, de qué manera la relación de influencia entre el poder y la comunicación se ha ido invirtiendo hasta alcanzar un punto de equilibrio de fuerzas e incluso un cambio de sentido de esa influencia hacia una dirección contraria: de la comunicación al poder.

Para desentrañar las claves del volátil escenario actual, un proceso histórico vivo y en plena transformación acelerada, sacudido además, por si fuera poco, por la pandemia de la enfermedad Covid-19, se ha hecho, cada vez más, imprescindible el recurso a la recogida de documentación directa, mediante testimonios de los propios actores, políticos y empresariales, del proceso ${ }^{11}$. Así, para la periodista Nieves Goicoechea, destacada referente del Grupo PRISA, en su calidad de jefa de la sección de Política de la Cadena SER desde septiembre de $2018^{12}$, «la crisis del modelo tradicional de medios de comunicación en España se hizo evidente en 2008 , a raíz de la crisis económica y financiera» ${ }^{13}$. La pérdida de ingresos económicos, por la bajada de publicidad, fue un fenómeno generalizado, que provocó la práctica desaparición de la prensa gratuita -de hecho, el único que sobrevivió fue el

11 Para este trabajo, se ha seguido una metodología de investigación cualitativa, por medio de encuestas semiestructuradas realizadas a profesionales del periodismo, expertos académicos, empresarios y políticos implicados en el proceso de transformación editorial. Se trata de una técnica de análisis y estudio fundada en el estudio de opiniones o actitudes que se realiza con pequeños grupos de personas, previamente seleccionadas por su elevada cualificación y relevancia en el ámbito objeto de estudio.

12 En 2008 fue nombrada secretaria de Estado de Comunicación, cargo que desempeñó hasta el año 2010. «Nieves Goicoechea, nombrada jefa de la sección de Política de la Cadena SER,» Cadena SER, https://cadenaser.com/ser/2018/09/21/ sociedad/1537530179_283015.html.

13 Nieves Goicoechea, (Secretaria de Estado de Comunicación (2008-2010).

Redactora jefe de Política de la Cadena Ser), entrevista por Juan Carlos Sánchez

Illán y César Luena López, 24 de abril de 2020. 
diario 20 Minutos-, el cierre de muchas cabeceras regionales y el despido de miles de periodistas. En paralelo, los medios periodísticos tuvieron que adaptarse a la revolución tecnológica que ya estaba en marcha y al progresivo cambio de hábitos del público. Al respecto, Goicoechea señala los que, a su entender, serían los tres grandes problemas del actual diseño empresarial. En primer lugar, la dudosa viabilidad del modelo de negocio de los medios convencionales, debido a que «la publicidad digital crece solo a dos dígitos y no compensa las pérdidas originadas por la bajada de la publicidad convencional, al menos en el caso de una empresa con altos costes estructurales» ${ }^{14}$; el deterioro de las condiciones laborales y profesionales, como consecuencia de la profunda crisis de los medios a raíz del crash económico de 2008, siendo «habitual convivir en las redacciones con la figura del periodista $o$ colaborador autónomo que se ve obligado a complementar varias colaboraciones para alcanzar un sueldo digno» ${ }^{15}$; $y$, finalmente, el fenómeno de la desinformación, que "alimenta la expansión de noticias falsas y bulos» ${ }^{16}$. Aun existiendo en España relativa pluralidad informativa, Goicoechea califica el panorama mediático como «excesivamente polarizado», como puede verse «en informaciones sesgadas que algunos medios publican ad hoc para servir a determinados intereses políticos o empresariales o para crear un estado de confusión colectiva", por lo que se han hecho necesarios los medios verificadores de noticias o fact-checkers, cada vez más presentes en el entorno digital ${ }^{17}$.

Un empresario de los medios tradicionales, como el CEO de Vocento, desde julio de 2011 y proveniente de Unidad Editorial, Luis Enríquez, tiene una perspectiva muy similar. Sitúa los obligados cambios editoriales, que se están produciendo a ritmo de vértigo, en el marco de la ubicua crisis del modelo de negocio. A su entender, «los medios tradicionales tuvieron, prácticamente hasta 2008, unos ingresos sólidos

14 Goicoechea, entrevista. 15 Goicoechea, entrevista. 16 Goicoechea, entrevista. 17 Goicoechea, entrevista. 
y crecientes, tanto por venta de ejemplares como por publicidad», ya que «los costes no requerían gran control y las propuestas imaginativas de ingresos no eran esenciales para la prosperidad de sus cuentas de resultados» ${ }^{18}$. Esto hacía posible que «herederos de grandes sagas de editores, poniendo más foco en los contenidos que en el negocio, pudieran llevar las riendas de sus compañías sin problema» ${ }^{19}$. Pero la crisis económica modificó este esquema. Según Enríquez, «el control de costes se volvió crucial», en un contexto en el que la clave era «la capacidad para anticiparse al mercado en ingresos en un entorno tecnológico nuevo e incierto» ${ }^{20}$.

En ese momento, las cuentas de resultados hicieron peligrar la continuidad de los grandes y medianos grupos editoriales, a la vez que se produjo el cambio de los perfiles al frente de los grupos de prensa, con el cambio de ejecutivos de medios por editores. "El éxito o el fracaso de esos ejecutivos de medios, a los que se les presuponen habilidades de gestión, pasa por la comprensión del negocio al que se dedican: edición de medios de información ${ }^{21}$, aclara el CEO de Vocento. Su propia empresa no estuvo al margen de estos cambios, de modo que tanto Alejandro Echevarría y José María Bergareche, hijos de los fundadores del Grupo Correo, como la familia Luca de Tena, histórica propietaria de $A B C$, dejaron sus puestos al frente de la compañía en manos de ejecutivos incorporados desde el mercado. En primer término,

\begin{abstract}
[...] «un ejecutivo procedente de un sector totalmente distinto - la telefonía-, después con un ejecutivo de la casa y después con otro ejecutivo del sector procedente de un grupo competidor. Aún así, herederos de las familias fundadoras se mantuvieron en la presidencia del grupo» ${ }^{22}$.
\end{abstract}

\footnotetext{
18 Luis Enríquez (Editor y CEO de Vocento), entrevista por Juan Carlos Sánchez Illán y César Luena López, 11 de mayo de 2020.

19 Enríquez, entrevista.

20 Enríquez, entrevista.

21 Enríquez, entrevista.

22 Enríquez, entrevista.
} 
Vocento y PRISA serían, en definitiva, dos de los grandes perjudicados en este proceso de crisis y reconversión forzada, precisamente por venir desde más arriba.

\section{La irrupción de los nuevos modelos editoriales del siglo XXI}

En la segunda década del siglo XXI el proceso de transformación y de volatilidad del panorama editorial se ha acelerado dramáticamente. Así, el que parecía imparable proceso histórico de concentración empresarial se ha visto modificado por el inesperado efecto, relativamente positivo -al menos en cuanto a diversidad de la oferta- del renovado ecosistema digital. Es evidente que se ha hecho imprescindible «reinventar los medios», puesto que los procesos de transformación, causados por la digitalización, están modificando a gran velocidad el escenario mediático ${ }^{23}$. En este sentido, el testimonio de un reconocido experto en teoría de la nueva comunicación mediática como Ángel Badillo ${ }^{24}$. Este autor apunta a causas básicamente económicas, de carácter universal, como origen de la irrupción de los medios digitales, tales como la emergencia del capitalismo global y el modo en el que ese proceso se incorporó a las industrias culturales, en particular el fenómeno al que se ha denominado en las últimas décadas financiarización. Para Badillo, procesos tan performativos como

[...] el aumento de tamaño de los grupos comunicacionales, su transmedialización, su transnacionalización y la necesidad de acudir a los mercados financieros para responder a esos desafíos hacen muy difícil que los grupos se mantengan en

\footnotetext{
23 De acuerdo con la tesis de Joaquín Aguirre Romero, «Reinventar la actualidad: los medios digitales y la transformación de las audiencias,» Espéculo. Revista de estudios literarios, $\mathrm{n}^{\circ} 37$ (2007), http://www.ucm.es/info/especulo/numero37/actualid.html.

24 Investigador principal del Real Instituto Elcano y profesor titular del Departamento de Sociología y Comunicación de la Universidad de Salamanca, su testimonio es singularmente clarificador y concluyente. En elReal Instituto Elcano se ha especializado en el análisis de «La sociedad de la desinformación, propaganda, fake news y la nueva geopolítica de la información». Documento de trabajo disponible en http://www. realinstitutoelcano.org/wps/wcm/connect/fc1e5338-b663-4254-943e-15b1d154e62e/ DT8-2019-Badillo-sociedad-de-desinformacion-propaganda-fake-news-y-nuevageopolitica-de-informacion.pdf?MOD=AJPERES\&CACHEID=fc1e5338-b663-4254943e-15b1d154e62e.
} 
torno no ya a grandes editores, sino a familias, como, por otro lado, vemos aún en algunos mercados.

Por ello,

[...] es difícil pensar que un solo editor pueda mantener el control de un grupo en este nuevo contexto. La digitalización, por otro lado, simplemente ha acelerado muchos de los rasgos que ya veníamos encontrando en los grupos de industrias culturales desde los años noventa.

En cuanto al papel de los poderes políticos, le confiere un mero desempeño «de contrapeso», porque

[...] en general los procesos de desregulación que acompañan, desde el último tercio del siglo XX, a la industria cultural benefician el cambio de ésta desde pequeños grupos férreamente dirigidos por criterios editoriales a grupos más transversales, férreamente -también- dirigidos por otros criterios, los financieros ${ }^{25}$.

$\mathrm{Al}$ abordar el origen de esta auténtica reconversión o, más bien, «reinvención de los medios», ahora desde la perspectiva política y más pegada al ejercicio profesional, Fernando Moraleda, quien fuera Secretario de Estado de Comunicación en una coyuntura crucial -ocupó el cargo desde septiembre de 2005 hasta abril de 2008- señala que el camino recorrido en el entorno digital desde su toma de posesión del cargo, en tan solo un quindenio, es prácticamente inconmensurable. Para Moraleda, «los grandes grupos de comunicación de aquel momento mantenían una estrategia empresarial que se podría adjetivar como aún analógica» ${ }^{26}$. La optimización de sus inversiones aspiraba, básicamente, a estar presente en tres medios: el escrito, el radiofónico y el audiovisual. Este era el caso en particular de PRISA, con El País y la Cadena Ser aunque con la ausencia de una televisión generalista en abierto, pero también el de otros como el Grupo Planeta.

25 Ángel Badillo (Investigador principal del Real Instituto Elcano. Profesor de la Universidad de Salamanca), entrevista por Juan Carlos Sánchez Illán y César Luena López, 22 de abril de 2020.

26 Fernando Moraleda (Secretario de Estado de Comunicación (2005-2008)), entrevista por Juan Carlos Sánchez Illán y César Luena López, 3 de mayo de 2020. 
Según su relato, el proceso de implantación de la Televisión Digital Terrestre (TDT) -y la correspondiente distribución de frecuencias- provocó «un cambio estructural en la recomposición de los medios y sus ámbitos de actuación, sobre todo por ser este el medio con mayor influencia de masas» ${ }^{27}$.

A partir de este primer desarrollo, se configuraron dos grandes bloques, que -según Moraleda- desplegaban «un modelo de tres patas: el Grupo PRISA, con El País, Cadena Ser y Canal Plus y el Grupo Planeta con La Razón, Onda Cero y Antena $3 »^{28}$. En relación con la gestión directa en el ámbito de sus responsabilidades en el Gobierno, Moraleda aseguró con rotundidad que, en aquella tesitura decisiva, «nuestra gestión política se basó en tres premisas: no interferir, no influir y no menoscabar» ${ }^{29}$. Moraleda no eludió tampoco el controvertido asunto de la posición del Grupo PRISA frente a la gestión de aquel Gobierno y de la aparición de La Sexta y Público, y sugiere que las razones hay que buscarlas, sobre todo, «en las diferencias de proyectos empresariales que compiten en el mismo mercado, más que en la influencia política del Gobierno», porque «atendimos las demandas de todos sin preguntar su línea editorial ni promovimos exclusiones de ningún tipo», de modo que «nunca hicimos exclusiones ni privilegiamos a unos frente a otros $»^{30}$.

En cuanto a la emergencia del periodismo digital, el periodista Gonzalo Vázquez ${ }^{31}$, recuerda, de forma empírica, gracias a sus años de trabajo y seguimiento efectivo en Moncloa, cómo al tradicional análisis que se hacía de la prensa diaria -El País, El Mundo, ABC, La Vanguardia, El Periódico y La Razón-, a partir del año 2008 se hizo preciso añadir y actualizar la información con la edición digital de los mismos medios. Y es que al «dicho de que no hay nada más viejo que el periódico de ayer», se unió el de «no hay

27 Moraleda, entrevista.

28 Moraleda, entrevista.

29 Moraleda, entrevista.

30 Moraleda, entrevista.

31 Director del Gabinete de la Secretaría de Estado de Comunicación entre 2006 y 2010. 
nada más viejo que un periódico de papel $»^{32}$. Esto provocó una sensación de flujo incesante de noticias que obligó a crear un equipo de seguimiento online para la prensa digital. Fue entonces cuando se incorporaron al resumen de prensa $-e l$ panadero, porque llega a primera hora- y a las reuniones de coordinación, a los digitales nativos, especialmente algunos de los más veteranos, como El Confidencial, El Confidencial Digital y el decano, Estrella Digital. A su juicio, el principal problema del nuevo entorno dominante es la pérdida de calidad de la información, para retener audiencias a cualquier precio, que «ha hecho que sea mucho más rápido y barato dar una opinión que informar sobre un hecho» ${ }^{33}$. Todo ello dibuja un panorama laboral relativamente dinámico, pero, al mismo tiempo, ciertamente sombrío para los nuevos medios digitales.

Para el catedrático de periodismo en la Universidad Carlos III de Madrid Carlos Elías, un experto en el análisis de la evolución de los medios ${ }^{34}$, las causas, más que sociales o políticas de aquella suerte de cataclismo o tsunami mediático digital son, esencialmente, de índole tecnológica y, por ende, económica, puesto que «la digitalización plena del siglo XXI ha posibilitado que no sea tan caro crear nuevos medios». Elías recalca, en particular, que buena parte de los principales fundadores de los nuevos periódicos digitales invirtieron, de hecho y como se verá en este trabajo, los ingresos que obtuvieron al ser despedidos en concepto de indemnización para crear sus empresas informativas. Por otro lado, advierte sobre la tendencia a implantar muros de pago en el futuro más inmediato, aunque eso pueda suponer que se sufra una pérdida de lectores e influencia, al menos a corto plazo. En cuanto al papel de los actores políticos, defiende que el mundo de la política no tuvo "que ver nada con la era digital», al contrario que ocurrió con la formación del duopolio televisivo, pero, aunque «les vino sobrevenido», supieron aprovecharlo,

32 Gonzalo Vázquez (Director del Gabinete de la Secretaría de Estado de Comunicación (2006-2010). Dircom en Repsol), entrevista por Juan Carlos Sánchez Illán y César Luena López, 30 de abril de 2020.

33 Vázquez, entrevista.

34 Autor de Big data y periodismo en la sociedad red (Madrid: Síntesis, 2015). 
pues «los políticos con millones de seguidores en las redes sociales son ahora medios de comunicación en sí mismos» ${ }^{35}$.

Esta es, asimismo, la tesis que sostiene el político y experto en el análisis multisectorial de medios de comunicación Óscar López. El que fuera, al mismo tiempo, secretario de Organización del PSOE en el periodo 2012-2014, en su calidad de experto en temas audiovisuales, fue el portavoz de los socialistas en el Congreso en esa materia entre los años 2004 y 2011, cargo desde el que fue ponente de tres leyes vitales en este campo: la Ley General Audiovisual, la primera de la historia, la Ley de la transición a la TDT y la de reforma de la corporación pública de RTVE ${ }^{36}$. Según su relato, el siglo XXI, en primer lugar, «ha democratizado la cantidad de emisores. Seguimos en una sociedad de grandes masas de receptores, pero se han multiplicado exponencialmente los emisores» ${ }^{37}$. En su opinión, han sido las nuevas tecnologías de la comunicación y la información las que «han transformado radicalmente el mundo editorial». Por lo que, básicamente,

[...] se trata de una cuestión meramente material y no ha afectado solo a la prensa. La apertura de un periódico tradicional implicaba unos costes descomunales comparados con un periódico digital. No es tan solo una cuestión de plantillas, también de compra o alquiler de espacios físicos, de imprentas y distribuidoras ${ }^{38}$.

Estos factores condicionantes, a nivel estructural, han desaparecido ahora definitivamente.

35 Carlos Elías (catedrático de Periodismo), entrevista por Juan Carlos Sánchez Illán y César Luena López, 23 de abril de 2020.

36 También es autor del libro Del 15M al procés: la gran transformación de la política española (Madrid: Ediciones Deusto, 2018). Resulta de interés, especialmente, para este trabajo el capítulo 12 del mismo, titulado «Guerrilla».

37 Óscar López (político, Secretario de Organización del PSOE (2011-2014) y Vicepresidente de la Comisión Mixta Congreso-Senado de RTVE (2016-2018)), entrevista por Juan Carlos Sánchez Illán y César Luena López, 11 de mayo de 2020. 38 López, entrevista. 
En palabras de José Vicente García Santamaría ${ }^{39}$, los factores básicos han sido, sin duda, la renovación tecnológica, que tuvo un fuerte impulso desde los años setenta, y a partir de la segunda mitad de los años noventa, así como la transformación digital, que, en España comenzó de forma tardía. Los empresarios españoles, en general, hicieron caso omiso a las abundantes señales que les llegaban desde otros países, fundamentalmente desde Estados Unidos, donde buena parte de los grupos familiares que controlaban conglomerados mediáticos en ese país comenzaron a desprenderse de parte de los activos periodísticos y a diversificar más sus empresas invirtiendo en el sector audiovisual. En España fue evidente, ya al comienzo de la década de los 90, que los grandes diarios ya no crecían en circulación, a excepción del diario El Mundo. Pero como la relativa bonanza económica persistía y los ingresos y los beneficios seguían aumentando nadie se atrevía a dar malas noticias y a tomar decisiones impopulares. Hasta que llegó la tremenda crisis económica de 2008, que "confirmó lo que ya muchos presentíamos: el fin traumático de un modelo de negocio sostenido en la prensa y aislado de las corrientes ganadoras y renovadoras -aunque más azarosasdel audiovisual y del entorno digital ${ }^{40}$.

Los resultados de la investigación y del trabajo de campo se presentan, a continuación, en tres grandes bloques, claramente diferenciados. Primero, se presenta el estudio y análisis de los medios más vinculados al periódico El País y al espectro progresista del campo político y mediático; es decir, Público, InfoLibre y ElDiario.es. En segundo lugar, se recoge el modelo del ecosistema conservador, ligado al periódico $E l$ Mundo, donde se abordan medios como El Independiente, El Español y Okdiario. Finalmente, se incluye como un ejemplo singular el caso del diario El Confidencial, por sus

39 Profesor del Departamento de Comunicación de la Universidad Carlos III de Madrid y autor del clarificador ensayo Los grupos multimedia españoles: análisis y estrategias. José Vicente García Santamaría, Los grupos multimedia españoles: análisis y estrategias (Barcelona: UOC, 2016).

40 José Vicente García Santamaría (Profesor titular del Departamento de Comunicación de la Universidad Carlos III de Madrid), entrevista por Juan Carlos Sánchez Illán y César Luena López pez, 28 de mayo de 2020. 
particularidades innovadoras, en cierto modo, pioneras, así como por su línea editorial orientada hacia un campo político ampliamente liberal.

La aventura editorial del diario Público y sus secuelas: InfoLibre y ElDiario.es

La trayectoria del diario Público.es, que se autodefine como «el diario digital puro más social de Europa», es paradigmática. Público ha tenido el histórico papel de ser la última cabecera diaria de ámbito nacional que nació y se desarrolló en papel -desde su fundación en septiembre de 2007 hasta febrero de 2012- y la primera que afrontó su transformación íntegra en un medio puramente digital. El problema de la Memoria Histórica española ha sido $-\mathrm{y}$ es- una de sus principales señas de identidad, a lo largo de sus años de recorrido, mostrándose en todo momento con un posicionamiento muy militante y combativo al respecto, con una marcada línea ideológica y editorial de izquierda ${ }^{41}$. En el fundamento de su línea editorial, el periódico considera que «la sociedad es injusta" y, por tanto, se erige como altavoz contra la injusticia social, económica o laboral con el fin de ayudar a denunciar y corregir las desigualdades. Su Director General, Chema Crespo, abandonó todos sus cargos políticos, en septiembre de 2007, para incorporarse a un periódico que, en sus palabras, «nació para incorporar espacios nuevos y como una consecuencia de los evidentes síntomas de agotamiento de la hasta entonces obligada referencia de la llamada prensa progresista identificada con El País» ${ }^{42}$. Crespo señala, por tanto, como principales factores impulsores, el envejecimiento del periódico insignia de PRISA, así como buena parte de sus lectores habituales. En consecuencia, identifica el nacimiento de Público con una nueva demanda por parte de «lectores jóvenes, urbanos y frustrados por una realidad que no les

41 Juan Carlos Sánchez Illán, "La Guerra Civil y el franquismo son noticia. Periodismo y memoria histórica,» en Historia y Memoria en red. Un nuevo reto para la historiografía, coord. Matilde Eiroa (Madrid: Síntesis, 2018), 171-198.

42 Chema Crespo (Director General de Público), entrevista por Juan Carlos Sánchez Illán y César Luena López, 3 de mayo de 2020. 
ofrecía oportunidades» ${ }^{43}$, en alusión a la tormentosa crisis que se avecinaba en 2008. Según su percepción de los hechos, el impacto fue inmediato y positivo y el crecimiento espectacular.

En cuatro años, sin ir más lejos, Público contaba con una tirada de unos cien mil ejemplares de promedio y «nuestras portadas acapararon muchos dosieres diarios de prensa» ${ }^{44}$. Asimismo, destaca lo innovador del diseño, una especie de "web en papel», que rápidamente atrajo, según su relato, a «jóvenes, inconformistas, urbanos, clases medias», por lo que «el objetivo se cumplió sobradamente en el terrenos de las ideas, de modo que el $15 \mathrm{M}$ estaba a punto de llegar» ${ }^{45}$; sin embargo, reconoce algunos problemas de diseño corporativo, ya que el precio fijado - de tan solo cincuenta céntimos de euro- devaluó su producto, de modo que, cuando lo subieron a un euro fue cuando más subieron en ventas, ya que, hasta entonces, «no éramos atractivos para el honrado gremio de los quiosqueros que viven del porcentaje de las ventas» ${ }^{46}$.

Las reacciones que recuerda, ante la irrupción de este medio periodístico, fueron, "desde el nerviosismo de quienes se sintieron atacados en su espacio", a los ataques provenientes de la derecha y la ultraderecha, además de «la agresividad de la izquierda liberalı ${ }^{47}$, representada por el grupo PRISA, ya que la salida de Público coincidió con las concesiones de las últimas licencias televisivas en abierto y el inminente apagón analógico. De hecho, desde la visión panorámica y experiencia que le proporciona haber sido Secretario de Estado de Comunicación, en una coyuntura breve, pero fundamental, desde abril de 2004 hasta septiembre de 2005, durante el primer Gobierno de José Luis Rodríguez Zapatero, el periodista y empresario Miguel Barroso consideró que lo referido por Chema Crespo fue clave para entender los acontecimientos posteriores. De hecho, durante la corta pero intensa etapa de Miguel Barroso, como Secretario de Estado,

43 Crespo, entrevista.

44 Crespo, entrevista.

45 Crespo, entrevista.

46 Crespo, entrevista.

47 Crespo, entrevista. 
se implantó la TDT en España, se fijó la fecha del apagón analógico y se concedió licencia a las cadenas de televisión la Sexta y Cuatro. En particular, cree que el diario Público

\begin{abstract}
[...] formó parte de un intento de configurar un grupo mediático progresista, que pretendía complementar ese espacio de influencia con PRISA, conglomerado mediático que disfrutaba del monopolio editorial en el ámbito del centro izquierda, mientras que en la derecha se lo venían disputando $A B C, L a$ Razón y El Mundo. El periódico, de hecho, nació con un planteamiento de integración vertical con La Sexta, aunque distintos factores impidieron que esa integración se completase ${ }^{48}$;
\end{abstract}

sin embargo, prosigue su relato Chema Crespo, con el telón de fondo de la crisis omnipresente de 2008, la caída del ingreso publicitario superó el cuarenta por ciento, pero Público seguía el mismo modelo, con una plantilla «de cerca de 200 personas, logística, impresión...», de tal modo que, "era cuestión de tiempo, de poco tiempo, que hubiera que afrontar la transición a digital. Algo que teníamos previsto a partir del quinto año pero que hubiéramos querido hacer de forma más ordenada y menos traumática» ${ }^{49}$. Por último, cree que los actores políticos siempre les observaron "con recelo, cuando no con abierta hostilidad», porque existía, a su juicio, «una alternancia más o menos comprensiva, un reparto de las esferas de influencia». «En ese contexto -añade-Público estorbaba. A la derecha, por aquello de que la pluralidad entraña riesgo y a la izquierda en el Gobierno, porque le resultaba molesto que se le recordaran las asignaturas pendientes», reflexiona, y esa especie de tierra de nadie también la sufrieron por su decidida apuesta por una salida social de la crisis, que «no fue entendida, desde luego por la derecha, pero tampoco por la izquierda institucional». Pero, finaliza Crespo, «todo es mucho más sencillo, nos limitamos a seguir los principios que motivaron nuestra aparición. Pagamos un alto coste, pero sobrevivimos con dignidad $»^{50}$.

48 Miguel Barroso (Secretario de Estado de Comunicación), entrevista por Juan Carlos Sánchez Illán y César Luena López, 30 de abril de 2020.

49 Crespo, entrevista.

50 Crespo, entrevista. 
La implosión del diario Público en papel, a comienzos de 2012, daría lugar, efectivamente, al nacimiento de dos nuevos medios digitales puros que pueden ser considerados, en buena medida, una especie de secuelas o spin-off: ElDiario. es e InfoLibre. Un fenómeno periodístico nada novedoso -aunque ahora acelerado por las nuevas tecnologías- y, de hecho, varias veces repetido en la historia del periodismo español ${ }^{51}$. Una nueva evidencia de que la fundación de un nuevo medio en el ecosistema de internet ya no es un proceso tan extraordinariamente complejo, desde el punto de vista organizativo y empresarial, como lo había sido hasta la omnipresencia de la red de redes. Estos diarios se presentan, de hecho, a sí mismos como continuadores de la línea editorial de Público, al menos en el ámbito de su aproximación ideológica a la historia de España. Sus promotores, Ignacio Escolar y Jesús Maraña, por añadidura, habían sido, con anterioridad, directores del desaparecido periódico en papel.

Dentro esta perspectiva histórica -y en idéntica línea de vindicación y compromiso memorialista-, hay que ubicar, por tanto, la trayectoria del diario InfoLibre.es, que ha recogido plenamente el testigo en cuanto a la preocupación constante por la problemática de la Memoria Histórica de la España más reciente. El que fuera el último director de la edición en papel del diario Público, Jesús Maraña, sería asimismo el fundador y director de InfoLibre, liderando un equipo de periodistas que puso en marcha esta nueva iniciativa periodística en marzo de 2013. Nació, de este modo, «gracias -en palabras de su promotor- a la reflexión de grupo de periodistas, fundamentalmente del área de Política, y que querían ejercer la actividad profesional de una forma más independiente», presumiendo, por ello, de «no haber contado nunca con ningún apoyo institucional $»^{52}$. Maraña, asimismo, confiesa que, como referente, siguieron la estela del diario digital francés Mediapart, «una cabecera fundada

51 Así, en mayo de 1879 de una crisis interna de El Imparcial nacía El Liberal; del mismo modo que en diciembre de 1919 de una marejada ideológica y empresarial en el seno del propio El Liberal nacería el diario La Libertad, entre otros casos relevantes. 52 Jesús Maraña (Fundador y Director Editorial de InfoLibre), entrevista por Juan Carlos Sánchez Illán y César Luena López, 1 de mayo de 2020. 
por periodistas, basada en la investigación rigurosa y ajena a intereses políticos o económico-financieros $\rangle^{53}$. En aquel momento, además, no existían en España otros arquetipos de periodismo por suscripción. En este sentido, la idea, sostiene, era «intentar un modelo que situase como prioridad el valor de un periodismo honesto que dependa fundamentalmente de lectores dispuestos a pagar, por poco que sea, por recibir una información fiable y contrastada ${ }^{54}$. Maraña advierte, al tiempo, que «la gran crisis de los medios en España -y en otros países- no era una crisis del periodismo sino del modelo de negocio y, sobre todo, una crisis de credibilidad, paralela a la de la política ${ }^{55}$. El curtido periodista opina, asimismo, que la ciudadanía perdió la confianza en los medios y en los periodistas, por estar «más al servicio de otros poderes que de los propios lectores o ciudadanos», lo que condujo al equipo fundador del diario digital a «ejercer el periodismo en su sentido de mimbre imprescindible de la democracia», ya que «era prioritario recuperar la credibilidad a través de una triple base: la independencia, la transparencia y el rigor ${ }^{56}$. Con una plantilla repleta de profesionales de reconocida trayectoria y credibilidad, con firmas colaboradoras muy reconocibles, InfoLibre consiguió muy pronto cierto eco e influencia política y mediática.

A pesar de que «en esa fase de arranque nos miraban desde el propio gremio periodístico como a verdaderos extraterrestres», ya que «los gurús y los ejecutivos de los grupos mediáticos seguían instalados en la defensa de la gratuidad absoluta en internet». Mientras que, desde la política, a su juicio, "no se entendía en absoluto la profunda crisis que afectaba a ambos actores de la democracia: políticos y medios o periodistas", en tanto que, "sin credibilidad, sólo alimentamos los populismos, la demagogia y la desinformación $»^{57}$. Maraña defiende que, en aquellas circunstancias, el modelo de negocio periodístico sufrió una "tormenta perfecta", en la que 
confluyeron «la pérdida de credibilidad, la profunda crisis económica y publicitaria - a partir de 2008- y los errores cometidos en la adaptación a la revolución digital». Para el veterano comunicador, hubo una incapacidad general a la hora de interpretar el impacto y significado de la aparición de internet. Así sucedió con los profesionales, pero no menos con la política, quien no se interesó en "proteger la función democrática de un periodismo fiable», como tampoco se hizo desde el mundo de la empresa o de las finanzas, quien al desentenderse del trabajo «en diferenciar la pura propaganda de la información de referencia», produjo que «la mayoría de los grupos de comunicación más importantes acumulen tal endeudamiento que están en manos de sus propios acreedores». De esta forma, concluye, les resulta aún más difícil recuperar credibilidad y rentabilidad». Maraña recela, por ello, del papel de la política en el cambio de modelo de negocio, por lo que presume repetidamente de no haber tenido «el menor apoyo desde ámbitos políticos», en los más de siete años que lleva en marcha InfoLibre. Acusa, además, a los poderes públicos de utilizar la publicidad institucional como si fuera un pesebre "que garantice el eco de la propaganda a cualquier nivel de las administraciones». Un hecho que considera un error, especialmente para las formaciones progresistas, "que siguen alimentando de forma opaca a medios cuya prioridad es precisamente imponer la ideología neoliberal, pero sobre todo sin respetar los principios de la independencia periodística $»^{58}$.

Por su parte, ElDiario.es, puesto en marcha el 18 de septiembre de 2012, ha convertido a la cuestión de la memoria y la historia de España reciente en uno de sus grandes ejes editoriales y, por tanto, de sus señas de identidad más visibles. El activo colaborador del diario y experto en memoria histórica Carlos Hernández de Miguel, que ejerció como director de Comunicación del PSOE, entre los años 2004 y 2008 , señala varias causas para explicar el cambio de modelo editorial. El cambio de propiedad, en primer lugar, así como la mutación «en la filosofía y los objetivos de buena parte de las empresas de comunicación», que hizo que los grandes editores

58 Maraña, entrevista. 
desaparecieran y fueran relegados a un segundo plano "por meros gestores empresariales o por magnates sin escrúpulos que pretenden utilizar los medios de comunicación para chantajear a los responsables políticos ${ }^{59}$. Hernández sostiene, por todo ello, que los que denomina "tiburones empresariales» conciben la información como mercancía y «dejan a un lado su trabajo de servicio público y se preocupan únicamente por la rentabilidad económica» ${ }^{60}$.

El verdadero problema, a su entender, es que

[...] el criterio deja de ser el de primar la relevancia de la información y pasa a moverse por el de los índices de audiencia y también por no molestar demasiado a los poderes políticos y empresariales/anunciantes de los que depende en buena medida la cuenta de resultados de la compañía periodistica ${ }^{61}$.

Por otro lado, denuncia la adquisición de diarios, radios y televisiones locales y regionales por parte de empresarios, la mayor parte de la construcción, "para fines espurios» tales como «atacar a alcaldes, concejales, presidentes autonómicos, instituciones y gobiernos que no les trataban con deferencia a la hora de decidir las adjudicaciones de obra pública» ${ }^{62}$. Hernández entona el mea culpa, afirmando que «todos lo sabíamos y no hicimos nada» ${ }^{63}$. Y más aún, si cabe, cuando reconoce que todos los cambios se produjeron en este contexto «de descrédito y de no poca corrupción cuando se produce la tormenta perfecta: crisis económica, triunfo de las nuevas tecnologías sobre los medios tradicionales y desafección de la ciudadanía a la política y también al periodismo» ${ }^{64}$. En esa línea, concluye, sin rehuir la polémica, que «las nuevas tecnologías han permitido el nacimiento y la expansión de verdaderos panfletos propagandísticos teledirigidos por la

59 Carlos Hernández (periodista y asesor de comunicación política), entrevista por Juan Carlos Sánchez Illán y César Luena López, 1 de mayo de 2020.

60 Hernández, entrevista.

61 Hernández, entrevista.

62 Hernández, entrevista.

63 Hernández, entrevista.

64 Hernández, entrevista. 
derecha política y mediática» ${ }^{65}$. En este espectro, destaca el papel, evidentemente, de las iniciativas afines de Ignacio Escolar y Jesús Maraña, «dos proyectos que contaban con importantes presupuestos de partida, pero que difirieron en la forma de financiarse, a través de socios y no solo de la publicidad, en el caso de El Diario, y de ofrecer sus contenidos en abierto en El Diario y de pago para suscriptores en InfoLibre» ${ }^{66}$. Esa diferencia de concepción explicaría buena parte del éxito de El Diario y parte del limitado crecimiento e influencia de InfoLibre. Muy recientemente, de hecho, ambos medios han suscrito, el 12 de junio de 2020, un acuerdo de sinergia y colaboración privilegiada, en una suerte de fusión fría que haga viables ambos proyectos en un contexto cada día más complicado ${ }^{67}$.

La crisis empresarial de El Mundo y la aparición de sus spin off: El Independiente, El Español y Okdiario

En el caso del diario El Mundo se ha reproducido, en buena medida, el modelo histórico del diario Público, en tanto que, a partir de la crisis de una potente empresa periodística, también se han desgajado diversos esquejes o ramas digitales, en una suerte -sui generis- de spin-offs: El Español de Pedro J. Ramírez; OKdiario de Eduardo Inda y El Independiente de Casimiro García Abadillo, publicaciones que continúan el estilo y la misma senda editorial que su diario matriz de Unidad Editorial (Unedisa), aunque con ciertos matices derivados, sobre todo, del peculiar talante e ideología de sus promotores. Así, para el periodista David Jiménez ${ }^{68}$, el resultado de esta transformación acelerada ha sido, fundamentalmente, una

65 Hernández, entrevista.

66 Hernández, entrevista.

67 Véase la motivación empresarial de ambos medios en sus ediciones de 12 de junio de 2020: «eldiario.es llega a un acuerdo de colaboración con infoLibre», El diario, Madrid, https://www.eldiario.es/redaccion/eldiarioes-llega-acuerdo-colaboracioninfoLibre_6_1037356279.html; «infoLibre llega a un acuerdo de colaboración con eldiario.es», infoLibre, Madrid, https://www.infolibre.es/noticias/medios/2020/06/12/ infolibre_llega_acuerdo_colaboracion_con_eldiario_es_107719_1027.html.

68 Director de $E l$ Mundo entre 2015 y 2016 y autor del polémico y mediático ensayo El Director Secretos e intrigas de la prensa narrados por el exdirector de 'El Mundo' (Madrid: Libros del KO, 2019). 
debilidad endémica de los medios, especialmente de los escritos. $\mathrm{Al}$ respecto, sitúa a la disrupción provocada por internet como como causa principal de los cambios producidos en la propiedad y la dirección de los grandes grupos editoriales, representados, hasta entonces, por sus propietarios históricos. Según su versión, «fueron los cambios de la nueva era digital, más que cualquier otro, los que contribuyeron al cambio de modelo» ${ }^{69}$. Hasta entonces, los elevados costes de lanzar y mantener una publicación -impresión, distribución...-protegían a esos grupos de la competencia y garantizaban la influencia de los editores clásicos, especialmente por el temor que despertaba en las elites políticas su capacidad de influir en la opinión pública. Pero, «al perder el monopolio de la información, y emerger nuevos players, esa influencia fue diluyéndose» ${ }^{70}$. Jiménez sostiene que los grupos tradicionales de prensa, carentes de visión histórica y de futuro, no comprendieron el alcance de la revolución digital y el impacto que tendría, de modo que «lectores, oyentes y espectadores empezaron a encontrarse con una oferta ilimitada de medios en la web y el poder se invirtió en su favor», de tal modo que «mientras la sociedad se sumaba a la revolución digital, los medios tradicionales se quedaban atrás» ${ }^{71}$. A su juicio, el caso más flagrante de este retraso es el de la prensa escrita, pues «frente al invento del coche, la apuesta de los grandes editores y las estructuras que los sucedieron fue mejorar los carruajes» ${ }^{72}$. Con el cambio de modelo ya en marcha, la crisis de 2008 agravó la situación de los medios tradicionales.

En ese contexto, y como medio de supervivencia, se produjo el acercamiento de los editores a los poderes económicos y políticos, "como un intento de obtener favores que garantizaran su supervivencia y permanecer relevantes» ${ }^{73}$. Se trata, en sus palabras, de «una estrategia que hoy sabemos

69 David Jiménez (Director de El Mundo (2015-2016) y Colaborador de The New York Times), entrevista por Juan Carlos Sánchez Illán y César Luena López, 9 de mayo de 2020.

70 Jiménez, entrevista.

71 Jiménez, entrevista.

72 Jiménez, entrevista.

73 Jiménez, entrevista. 
fallida, porqueaceleróeldesprestigiodesus marcasperiodísticas y facilitó la emergencia de nuevos competidores digitales, que entendieron la nueva relación con el público que exigían los tiempos» ${ }^{74}$. Mientras que los nuevos medios resultaban rentables, los tradicionales sufrían «financieramente las consecuencias de su lentitud en adaptarse, la permanencia de viejas estructuras y la falta de credibilidad por su cercanía al poder» ${ }^{75}$, sentencia. Desde su experiencia en la dirección del periódico El Mundo, critica, además, la gestión que el grupo propietario, Unidad Editorial, desempeñó en esos momentos, al no saber adaptarse al nuevo ecosistema, mientras trataban de recrearse en el antiguo, ya moribundo. Por su parte, los actores políticos, «contribuyeron a alargar la vida de los medios tradicionales de forma ficticia a través de concesiones de radio y televisión, acuerdos en publicidad institucional y favores en función de que un grupo determinado les apoyara» ${ }^{76}$. El exdirector de $E l M u n d o$, sin esquivar la polémica, califica esta relación como de «matrimonio incestuoso entre medios y política», relación que proviene, razona, de la Transición y que «se reforzó durante las siguientes décadas», porque «los grandes editores siempre tuvieron un vínculo fuerte con un ala del poder que garantizara que, al menos en los periodos en que esta estuviera en el poder, las decisiones que se tomaran protegieran sus intereses» ${ }^{77}$. Para terminar, explica que, «a diferencia de otros países, como Estados Unidos o Alemania, el muro que debería separar prensa y política nunca existió en España, donde los políticos han hecho a menudo de periodistas y los periodistas de políticos». Así pues, «en lugar de fomentar la transformación digital de los medios tradicionales, el poder político ha tendido a buscar su control», concluyendo, de forma lapidaria, que «en gran parte, lo ha conseguido» ${ }^{78}$.

Por su parte, Casimiro García Abadillo, director de El Independiente, se planteó, al abandonar la dirección de El Mundo, el continuar como columnista en ese mismo

74 Jiménez, entrevista.

75 Jiménez, entrevista.

76 Jiménez, entrevista.

77 Jiménez, entrevista.

78 Jiménez, entrevista. 
periódico o en otros, "además de colaborar en programas de radio y televisión, o bien crear un periódico nuevo en el que lo prioritario fuera la información, por encima de las ideologías» ${ }^{79}$. Este es el origen editorial, en septiembre de 2016, del diario digital El Independiente, que recibió el impulso, desde el inicio, de periodistas consagrados en el panorama comunicativo nacional, como es el caso de la veterana Victoria Prego. Compitiendo en el mismo segmento ideológico y editorial que su matriz de centro derecha, tiene como prioridad la información política, económica y la opinión; aunque no cuenta con una sección o etiqueta específica para ocuparse de cuestiones históricas. García Abadillo asegura, al respecto, que «las intenciones editoriales eran modestas», de modo que no se pretendía «hacer un medio de masas, sino más bien un periódico de influencia, que no buscara el clickbait» ${ }^{80}$. Sobre el cambio de modelo de negocio experimentado por todos los medios, explica que «el papel se desplomó y dejó de ser referencia para la información", de tal forma que «hoy el lector se ha acostumbrado al periódico digital, que le da la información y la opinión de forma casi instantánea. Esta nueva manera de suministrar información ya no tiene marcha atrás» ${ }^{81}$. Aunque, según su versión, el mundo de la política reaccionó con desconfianza, pues «vivían todavía en el siglo pasado», mientras que "ahora ya no pueden vivir sin los periódicos digitales y las redes sociales, que forman parte del paisaje político y cada vez desempeñan un papel más importante» ${ }^{82}$.

El Español, por su parte, es un diario digital que comenzó su publicación en octubre de 2015. Está fundado y dirigido por Pedro J. Ramírez, afamado exdirector de Diario 16 y durante más de dos décadas auténtico alma mater de El Mundo. Este nuevo medio, también muy marcado por la personalidad de su célebre y mediático director, evidencia en sus páginas un más que notable interés por todo lo relacionado

79 Casimiro García Abadillo (Fundador y director de El Independiente), entrevista por Juan Carlos Sánchez Illán y César Luena López, 18 de abril de 2020.

80 García Abadillo, entrevista.

81 García Abadillo, entrevista.

82 García Abadillo, entrevista. 
con el impacto noticioso de la historia más reciente de España, mostrándose como una de las etiquetas temáticas más activas y constantes en el tiempo; su posicionamiento es liberal, en sentido amplio, y su tono relativamente ecléctico. El veterano periodista e historiador Juan Carlos Laviana, cofundador y director adjunto de El Mundo -entre 1989 y 2016- y actualmente periodista freelance en El Español, apunta, como fundamentación de sus inicios y la compleja búsqueda de un espacio propio, a la llegada de una nueva generación, «la llamada nativa digital», quienes, como «consumidores masivos de información, obligan a los medios a cambiar la forma de presentar y transmitir las noticias» ${ }^{83}$. Además, también encuentra una relación directa con los cambios políticos, que para él son el fin del bipartidismo y la emergencia de partidos nuevos, motivo por el que «la prensa se ve obligada a atender varias sensibilidades»" ${ }^{84}$. Este fenómeno "se produce sobre todo a partir del 15-M. Hasta entonces, había medios de izquierda y de derecha, sin más matices». Mención aparte, prosigue, «merecen las redes sociales, instrumento de comunicación sin el que no se entendería la política actual» ${ }^{85}$. Por último, sugiere que medios como El Español "han de adaptarse al tiempo en el que se vive, tanto en la línea editorial como la forma de presentar y difundir información» ${ }^{86}$.

Muy diferente es el modelo de negocio elegido por Eduardo Inda para el lanzamiento de OKdiario, un periódico online fundado en septiembre de 2015 por el controvertido periodista y mediático tertuliano, quien abordó la creación de este medio tras abandonar su cargo de director adjunto del diario $\mathrm{El}$ Mundo. Su línea editorial, con tintes muy personalistas, se enmarca en el espectro político de la derecha liberal de tinte más populista y desacomplejado. Este diario se ha convertido, además, en un notable ejemplo del llamado «negocio de la manipulación digital», generando ingresos,

83 Juan Carlos Laviana (Director adjunto de El Mundo (1989-2016) y colaborador de El Español (desde 2016)), entrevista por Juan Carlos Sánchez Illán y César Luena López, 6 de mayo de 2020.

84 Laviana, entrevista.

85 Laviana, entrevista.

86 Laviana, entrevista. 
fundamentalmente, a través del aprovechamiento de Google y de otras redes de publicidad online.

Es bien sabido, de hecho, que «los algoritmos utilizados en las plataformas de búsqueda y en las redes sociales pueden ser propulsores de difusión de desinformación», de modo «que los sitios web o las noticias que contengan información falsa aparezcan primero», al mismo tiempo que «la incertidumbre se viraliza en una esfera pública digital donde las noticias falsas tienen un 70 por ciento más de probabilidades de ser retuiteadas que las verdaderas ${ }^{87}$. Su éxito, como el de otras páginas de corte similar, que han ganado audiencia recientemente, se debe en buena parte al poderoso altavoz de las redes sociales, pero también al lucrativo negocio de la publicidad automática por Internet, que recompensa un tipo de contenido que muchos académicos y políticos creen que está dañando la conversación pública ${ }^{88}$.

\section{El exitoso modelo de El Confidencial}

Un prototipo también muy diferente y mucho más aclamado, en términos de rentabilidad, prestigio y credibilidad, es el que ofrece $E l$ Confidencial. Dentro de un espectro ideológico genéricamente liberal, cabe situar la trayectoria de este diario generalista. Con una línea editorial poco definida -ni a izquierdas ni a derechas- y relativa variedad de colaboradores, ocupa un lugar privilegiado en su segmento de digitales nativos, por ser el de mayor audiencia según todos los medidores. Su posicionamiento es ecléctico, como corresponde a una ideología que podría calificarse también como centrista, dando voz a autores de diversas sensibilidades y abordando toda la problemática relacionado con el pasado histórico como una noticia más, sin grandes dramatismos. Por todo ello, $E l$

87 Daniel Innerarity y Carme Colomina, «La verdad en las democracias algorítmicas,» Revista CIDOB d'Afers Internacionals, ${ }^{\circ} 124$ (abril de 2020): 11-23.

88 De acuerdo con el análisis de Fernando Peinado y Daniel Muela, «Noticias falsas. El negocio de la manipulación digital en España», El País, 23 de mayo de 2018, https://elpais.com/politica/2018/05/17/actualidad/1526571491_535772.html. 
Confidencial, ha sido valorado como líder en credibilidad, según una encuesta de la Universidad de Valencia ${ }^{89}$.

El periodista Nacho Cardero es el director de $E l$ Confidencial, desde marzo de 2011. Un periódico digital que había nacido en mayo de 2001, según su testimonio, «en el garaje de una casa en la calle Cardenal Herrera Oria de Madrid, queriendo emular esas cuartillas mecanografiadas y anónimas que hace décadas llegaban a los principales centros de poder» ${ }^{90}$. Conscientes del riesgo, pero también de la oportunidad que brindaba internet, el nuevo periódico nació "casi como un divertimento», asegura ${ }^{91}$. Desde su aparición, $E l$ Confidencial no paró de crecer. Según su director,

[...] tuvimos la suerte de nacer en el lugar adecuado, en el momento exacto. Ni demasiado pronto, ni demasiado tarde. Había una demanda de información, una necesidad que nosotros satisfacíamos, y apenas había competencia. Eso nos permitió crear una sólida base de lectores desde el principio, que son muy fieles ${ }^{92}$.

Además, pronto se convertiría en un diario de información general, porque «a pesar del nombre de nuestra cabecera, dejamos de ser un confidencialı ${ }^{93}$. Hoy, el periódico cuenta con casi 170 trabajadores, una plantilla prácticamente similar al nivel de otras grandes cabeceras de papel, y es rentable desde el año II. Presume, por ello, de constituir «un modelo de empresa periodística que ha sabido maridar calidad con rentabilidad, una independencia financiera que también le ha proporcionado independencia editorial $»^{94}$. Cardero defiende,

$89 \mathrm{El} \mathrm{Confidencial}$ es el único diario nacional que aprueba en credibilidad $(5,3)$ según los resultados de la Encuesta sobre Medios y Comunicadores, con más de 5.400 respuestas. «El Confidencial, líder en credibilidad según una encuesta de la Universitat de València», El Confidencial, 24 de enero de 2017, https://blogs. elconfidencial.com/comunicacion/en-contacto/2017-01-24/el-confidencial-credibilidadideologia-encuesta-medios-de-comunicacion_1320564/.

90 Nacho Cardero (Director de El Confidencial), entrevista por Juan Carlos Sánchez Illán y César Luena López, 21 de mayo de 2020.

91 Cardero, entrevista.

92 Cardero, entrevista.

93 Cardero, entrevista.

94 Cardero, entrevista. 
además, la labor determinante del periodista, «si atendemos al momento de España en particular y el mundo en general», por lo que «los medios de calidad se erigen, o deberían hacerlo, en herramienta de regeneración democrática ${ }^{95}$. El Confidencial destaca, especialmente, por su periodismo de investigación y por haber sido los primeros en España en impulsar una sección de periodismo de datos o fact checking.

En el repaso de sus casi veinte años de andadura, Cardero destaca, prolijo y orgulloso, los principales logros informativos de la cabecera, ya que

$$
\begin{aligned}
& \text { [...] hemos publicado los Papeles de Panamá junto a } \\
& \text { otros medios, un trabajo de investigación sobre la mayor } \\
& \text { fábrica del mundo de sociedades opacas que destapaba los } \\
& \text { entramados de grandes y poderosas fortunas para ocultar } \\
& \text { su patrimonio y evadir al Fisco. Nos valió un Pulitzer. } \\
& \text { Denunciamos los agujeros de la salida a Bolsa de Bankia, } \\
& \text { sorteando a las instituciones, que presionaron sin éxito para } \\
& \text { que no lo hiciésemos. Años después seríamos víctimas de } \\
& \text { una campaña similar con Banco Popular. Nos advertían de } \\
& \text { que desestabilizaríamos el sistema. Dimos en exclusiva la } \\
& \text { abdicación del rey Juan Carlos. Publicamos la Lista Falciani } \\
& \text { [... }{ }^{96} \text {, }
\end{aligned}
$$

finaliza, coincidiendo con su $20^{\circ}$ aniversario, además, el periódico ha realizado una transformación de su modelo de negocio, al iniciar el 22 de junio de 2020 su conversión al modelo de suscripción, como se han visto obligados a hacer casi todos los medios.

Muy significativamente, El Confidencial también viviría su propia disidencia interna, con la aparición de Vozpópuli, un periódico digital fundado en 2011 por quien había sido su fundador, el periodista Jesús Cacho, tras haber abandonado El Confidencial y con la pertinente indemnización del despido. Cacho, un histórico del periodismo español, había trabajado durante los años 80 y 90 del siglo pasado en los tres grandes

95 Cardero, entrevista. 96 Cardero, entrevista. 
periódicos impresos de la democracia española: $A B C$, El País y El Mundo.

«En los tres se había encontrado con muchas dificultades para escribir con plena libertad, dadas las ataduras que tenían esas cabeceras con el poder establecido. Eso fue lo que llevó a, aprovechando las ventajas que ofrece internet, desarrollar un nuevo periódico digital como Vozpópuli» ${ }^{97}$,

en palabras de su Director adjunto, Álvaro Nieto, quien había sido redactor jefe de El País, entre otras responsabilidades. Nieto asegura que su salida a la calle no supuso un gran acontecimiento histórico en el ecosistema mediático, ya que «salvo que se tengan muchos recursos para invertir en publicidad y contratar una gran plantilla de inicio, es difícil que el nacimiento de un periódico digital revolucione el panorama ${ }^{98}$. Este lanzamiento editorial fue posible, una vez más, gracias a internet, que ha democratizado el acceso a la información y ha permitido la multiplicación de medios, debido a que no se requiere una gran inversión para montar un periódico. La desaparición de los grandes editores de papel es -a su entender- «hasta cierto punto lógica en un mundo en el que se necesitan muy pocos euros para poder informar», en tanto que, «para desarrollar un periódico de papel se necesitaba mucho capital, para pagar costes de distribución e impresión que hoy han desaparecido por completo» ${ }^{99}$. Por ello, «la apuesta de Vozpópuli siempre fue a largo plazo, ir paso a paso, con un modelo de negocio muy ajustado en gastos y sin incurrir en deuda para no perder libertad frente a los acreedores y anunciantes» ${ }^{100}$. En consecuencia, «nueve años después y con casi diez millones de lectores mensuales, Vozpópuli está en plena madurez y en disposición de pelear cara a cara con todos los actores mediáticos que hay en España» ${ }^{101}$. Además, Nieto no cree que «los políticos hayan tenido que ver en este cambio de modelo del negocio periodístico», sino que "ha sido más

97 Álvaro Nieto (Director adjunto de Vozpópuli), entrevista por Juan Carlos Sánchez Illán y César Luena López, 27 de mayo de 2020.

98 Nieto, entrevista.

99 Nieto, entrevista.

100 Nieto, entrevista.

101 Nieto, entrevista. 
bien una consecuencia del cambio tecnológico y, por otro lado, del deseo de los ciudadanos de recibir otro tipo de fuentes de información distintas a las tradicionales» ${ }^{102}$. Pese a todo, «en Vozpópuli tenemos un interés especial por la historia porque solo con memoria es posible aprender del pasado. Tenemos una sección especial de Historia y solemos publicar artículos sobre ello» ${ }^{103}$. Otro medio recién llegado, en busca de su espacio, en definitiva, y con mucho recorrido todavía por delante.

\section{Conclusiones}

El estudio de las trayectorias históricas de los grandes grupos editoriales, ligados a fuertes personalidades, así como el análisis inmediato de las experiencias digitales surgidas en las últimas dos décadas, pretende constituir un primer paso para un balance histórico -y empírico-, con testimonios de primera mano, de un número de casos concretos suficiente. Se trata de demostrar que, al menos en el caso español, la transformación del mundo editorial y su nueva configuración y significación social, económica y política, se ha producido en un contexto causal homogéneo a todos los casos y ha generado unas consecuencias globales, de conjunto, que determinan la existencia de un fenómeno histórico concreto. En definitiva, la investigación realizada demuestra cómo la transformación del modelo editorial en España ha estado encuadrada en el marco de una serie de cambios globales, los cuales han condicionado la evolución de este proceso a nivel mundial. El desarrollo tecnológico y su impacto en la comunicación y en la información fue el germen del gran proceso de transformación editorial. Seguidamente, las generaciones más jóvenes irrumpieron con una modificación sustancial del tipo de consumo de información, en demanda de un tipo de producto comunicacional más ágil, abierto, directo y sencillo de manejar que el formato tradicional del periódico en papel.

Las principales conclusiones, como variables causales e impacto general del modelo español, dentro del proceso de

102 Nieto, entrevista. 103 Nieto, entrevista. 
transición editorial que se está dando en todo el mundo se pueden sintetizar en tres apartados.

La crisis económica y su repercusión directa en la pérdida de ingresos publicitarios es la primera y principal causa de origen del cambio en el modelo de negocio editorial. La dimensión de las empresas periodísticas era imposible de mantener en un contexto de ingresos tan reducidos y con muy poca expectativa de mejora, por lo que la revisión del tamaño de las empresas pasó a ser una prioridad para todos los grupos periodísticos, que tuvieron que prescindir, a la vez, de un importante número de profesionales. Parece, en definitiva, más que evidente e indiscutible que el periodismo de internet ha provocado una disrupción resolutiva en el proceso de concentración mediática, iniciado a comienzos del siglo XX y que hasta hace bien poco parecía imparable. Gracias al testimonio directo de sus promotores, se ha podido verificar empíricamente cómo, en la segunda década del siglo XXI, ha sido cada vez más frecuente la irrupción de nuevos medios digitales de ideología y líneas editoriales muy diversas. En muchos casos, como se ha podido comprobar, se ha tratado de ramas salidas de un tronco común, algo que no es en absoluto excepcional a lo largo de la historia del periodismo español. Probablemente, la novedad más llamativa, históricamente, ha tenido que ver con la relativa simplificación de los procesos empresariales de edición que ha suscitado la ubicuidad de internet, puesto que ya no son necesarias las costosas rotativas y linotipias de antaño.

De forma simultánea, la irrupción masiva de las nuevas tecnologías de la información y la comunicación, su accesibilidad y uso generalizado, la digitalización general de la sociedad, especialmente de los jóvenes, unido a la proliferación de numerosas aplicaciones de redes sociales, propiciaron un nuevo tipo de comportamiento y de consumo digital, que ha ido sustituyendo gradual pero imparablemente al analógico. Por añadidura, como se ha podido verificar, la crisis económica y la desigualdad social actuaron como acicates de este proceso, al provocar una crisis de las grandes empresas, la precarización del trabajo en el sector y, como suma de todo ello, generar 
las condiciones propicias, económicas y sociales, para la aparición prolija de diversos proyectos de diarios digitales, que consolidaron la tendencia de cambio iniciada por los cambios tecnológicos y por el relevo generacional. Todo ello configuró la aparición de una nueva demanda social y, por tanto, un nuevo mercado de la información. La crisis social que generó la Gran Recesión de 2008 y la desigualdad generada en amplias capas de la población, espoleó el sistema político español, que en adelante evolucionó hacia el multipartidismo, con la pérdida de poder y espacio de los dos grandes partidos predominantes hasta entonces desde los años 80 del siglo pasado.

Así las cosas, con un nuevo mercado por ocupar, una parte importante de los profesionales que tuvieron que salir de los grandes grupos históricos apostaron por modelos más horizontales y participativos, exclusivamente digitales, en la línea de las nuevas realidades y de las nuevas tendencias de consumo: jóvenes y clases trabajadoras demandantes de una información distinta, más directa y rápida, y, a ser posible, gratuita. Esta especie de cooperativismo digital era al siglo XXI lo que las corporaciones de papel habían sido en el siglo $\mathrm{XX}$ : actores económicos y políticos simultáneamente. Al desaparecer, en muchos casos, la dependencia financiera de la publicidad institucional, medio por el que los poderes políticos intervenían en el sector, muchos de estos medios han ejercido el periodismo con más autonomía respecto al poder político, inaugurando unas nuevas relaciones entre el periodismo y la política, de una menor dependencia por parte del primero y de menos poder, por parte de la segunda.

Finalmente, los distintos actores políticos han sido más espectadores que actores de este vertiginoso y dinámico cambio. Con el nuevo escenario, en el que las empresas históricas, por así decir, están adaptando también sus estructuras y modelos al nuevo paradigma predominante, conviven con los diarios digitales consolidados y con los de más reciente creación, los actores políticos tratan de ordenar o de condicionar un nuevo panorama que se ha terminado de configurar a partir de una situación económica, social y tecnológica que ha contribuido a transformar también la política, que son las características 
básicas del modelo español de transición editorial y de cambio del modelo analógico, fundado en el papel, hacia el digital basado en la red. De este modo, se demuestra que el caso español viene marcado por tres características muy determinadas, abordadas a lo largo de los distintos capítulos de la investigación. En primer lugar, la fragmentación que puede observarse en el panorama mediático, ligada a la existencia de distintos bloque políticos, lejos de disolverse en el nuevo escenario, se consolidó e incluso agudizó, pues, como se ha evidenciado, existen tres grandes bloques de espacios mediáticos, reforzados por la creación de los nuevos diarios digitales: el campo progresista, el conservador y el liberal. En segundo lugar, es de destacar la capacidad de iniciativa profesional y de asociación que se da en muchos de los modelos empresariales, lo que se proyecta después en el modelo de suscripción del lector, como gran sustentador material del proyecto. Esta realidad permitió que el capital bancario o industrial perdiera cuota de poder e influencia en los medios de comunicación y que lo ganaran los profesionales, en primer término, y los lectores y los ciudadanos, posteriormente.

Por último, y para finalizar, la configuración final del panorama editorial en España y su completa digitalización, conviviente con los proyectos tradicionales renovados, también ha supuesto una inversión de las relaciones de poder, como ha quedado igualmente verificado, pues a la pérdida progresiva de voz e influencia directa de los poderes económicos, se le ha sumado la pérdida en esos mismo terrenos del poder político. Una circunstancia que los diarios digitales han aprovechado para activar cierta lógica de la inversión, aprovechando el enorme caudal de influencia que otorga la red en forma de presión informativa y editorial hacia los actores políticos, quienes están ahora más sujetos que en el pasado al control que impone el chequeo y comprobación de las informaciones y la demanda permanente por parte de la sociedad de transparencia absoluta, al menos en todo lo que esté relacionado con los intereses generales. 


\section{Bibliografía}

Aguirre Romero, Joaquín. "Reinventar la actualidad: los medios digitales y la transformación de las audiencias.» Espéculo. Revista de estudios literarios, $\mathrm{n}^{\circ} 37$ (2007). Acceso el 2 de junio de 2020, http://www.ucm.es/info/especulo/numero37/actualid. html.

Badillo, Ángel. «La sociedad de la desinformación, propaganda, fake news y la nueva geopolítica de la información». Documentos de Trabajo Real Instituto Elcano. Acceso el 2 de junio de 2020. http://www.realinstitutoelcano.org/wps/ wcm/connect/fc 1e5338-b663-4254-943e-15b1d154e62e/ D T 8-2019-Badillo-sociedad-de-desinformacionpropaganda-fake-news-y-nueva-geopolitica-de-informacion. pdf?MOD=AJPERES\&CACHEID=fc1e5338-b663-4254-943e$15 \mathrm{~b} 1 \mathrm{~d} 154 \mathrm{e} 62 \mathrm{e}$.

Cabrera, Mercedes. Jesús de Polanco, capitán de empresas. Barcelona: Galaxia Gutenberg, 2015. . «Jesús de Polanco and the Prisa Group.» Journal of Evolutionary Studies in Business Vol. 3, $\mathrm{n}^{\mathrm{o}} 1$ (2018): 247-280.

Elías, Carlos. Big data y periodismo en la sociedad red. Madrid: Síntesis, 2015.

García Santamaría, José Vicente. Los grupos multimedia españoles: análisis y estrategias. Barcelona: UOC, 2016.

Innerarity, Daniel, y Carme Colomina. «La verdad en las democracias algorítmicas.» Revista CIDOB d'Afers Internacionals, $\mathrm{n}^{\circ} 124$ (2020): 11-23.

Jiménez, David. El Director. Secretos e intrigas de la prensa narrados por el exdirector de 'El Mundo'. Madrid: Libros del KO, 2019.

Juana López, Jesús de. La posición centrista durante la Segunda República: (el periódico 'Ahora', 1930-1936). Santiago de Compostela: Servicio de Publicaciones de la Universidad, 1988.

López, Óscar. Del 15M al procés: la gran transformación de la política española. Madrid: Ediciones Deusto, 2018. 
Sánchez Illán, Juan Carlos. «La edición de periódicos y la empresa periodística.» En Historia de la edición en España (18361936), editado por Jesús Martínez, 397-414. Madrid: Marcial Pons, 2001.

«Los espacios del poder político y periodístico en la Edad de Oro del periodismo español.» En La sociedad urbana en el Madrid contemporáneo, editado por Jesús Martínez y Luis Enrique Otero, 89-102. Madrid: Libros de la Catarata, 2018.

. «La Guerra Civil y el franquismo son noticia. Periodismo y memoria histórica.» En Historia y Memoria en red. Un nuevo reto para la historiografía, coordinado por Matilde Eiroa, 171-198. Madrid: Síntesis, 2018.

Toll, Gil. Heraldo de Madrid, tinta catalana para la II República española. Sevilla: Renacimiento, 2013.

\section{Fuentes primarias}

\section{Entrevistas}

Badillo, Ángel. Entrevista por Juan Carlos Sánchez Illán y César Luena López. 22 de abril de 2020.

Barroso, Miguel. Entrevista por Juan Carlos Sánchez Illán y César Luena López. 30 de abril de 2020.

Cardero, Nacho. Entrevista por Juan Carlos Sánchez Illán y César Luena López. 21 de mayo de 2020.

Crespo, Chema. Entrevista por Juan Carlos Sánchez Illán y César Luena López, 3 de mayo de 2020.

Elías, Carlos. Entrevista por Juan Carlos Sánchez Illán y César Luena López, 23 de abril de 2020.

Enríquez, Luis. Entrevista por Juan Carlos Sánchez Illán y César Luena López, 11 de mayo de 2020.

García Abadillo, Casimiro. Entrevista por Juan Carlos Sánchez Illán y César Luena López. 18 de abril de 2020.

García Santamaría, José Vicente. Entrevista por Juan Carlos Sánchez Illán y César Luena López. 28 de mayo de 2020. 
Goicoechea, Nieves. Entrevista por Juan Carlos Sánchez Illán y César Luena López. 24 de abril de 2020.

Hernández de Miguel, Carlos. Entrevista por Juan Carlos Sánchez Illán y César Luena López. 1 de mayo de 2020.

Jiménez, David. Entrevista por Juan Carlos Sánchez Illán y César Luena López. 9 de mayo de 2020.

Laviana, Juan Carlos. Entrevista por Juan Carlos Sánchez Illán y César Luena López. 6 de mayo de 2020.

López, Óscar. Entrevista por Juan Carlos Sánchez Illán y César Luena López. 11 de mayo de 2020.

Maraña, Jesús. Entrevista por Juan Carlos Sánchez Illán y César Luena López. 1 de mayo de 2020.

Montiel Armada, Entrevista por Juan Carlos Sánchez Illán y César Luena López. 12 de mayo de 2020.

Moraleda, Fernando. Entrevista por Juan Carlos Sánchez Illán y César Luena López. 3 de mayo de 2020.

Nieto, Álvaro. Entrevista por Juan Carlos Sánchez Illán y César Luena López. 27 de mayo de 2020.

Vázquez, Gonzalo. Entrevista por Juan Carlos Sánchez Illán y César Luena López. 30 de abril de 2020.

\section{Fuentes hemerográficas}

«eldiario.es llega a un acuerdo de colaboración con infoLibre». El diario, Madrid. https://www.eldiario.es/redaccion/eldiarioesllega-acuerdo-colaboracion-infoLibre_6_1037356279.html.

«infoLibre llega a un acuerdo de colaboración con eldiario. es». infoLibre, Madrid. https://www.infolibre.es/noticias/ medios/2020/06/12/infolibre_llega_acuerdo_colaboracion_con_ eldiario_es_107719_1027.html.

«El Confidencial, líder en credibilidad según una encuesta de la Universitat de València». El Confidencial, 24 de enero de $2017 . \quad$ https://blogs.elconfidencial.com/comunicacion/encontacto/2017-01-24/el-confidencial-credibilidad-ideologiaencuesta-medios-de-comunicacion_1320564/. 
«Nota necrológica de D. Luis Montiel Balanzat». Agencia Cifra-EFE, $A B C$, Madrid, 17 de julio de 1976.

«Nota necrológica de D. Luis Montiel Balanzat». Agencia Europa Press, La Vanguardia, Barcelona, 17 de julio de 1976.

Gold, Howard R., «It's the End of the Media Moguls Era», The Wall Street Journal, Nueva York, 18 de agosto de 2005. https:// www.wsj.com/articles/SB112436847596016582.

Peinado, Fernando, y Daniel Muela. «Noticias falsas. El negocio de la manipulación digital en España», El País, 23 de mayo de 2018. https://elpais.com/politica/2018/05/17/ actualidad/1526571491_535772.html.

\section{Cuestionario básico completo}

¿Qué motivaciones profesionales y empresariales le llevaron a impulsar la iniciativa?

¿Qué impacto tuvo la aparición de su publicación en el panorama mediático y político?

En su opinión, ¿cuáles fueron las principales causas sociales, políticas y económicas del cambio de modelo al que hacemos referencia?

¿Qué papel tuvieron los actores políticos principales en este cambio de modelo?

¿Considera que la historia de la España más reciente ocupa un lugar destacado en su línea editorial y secciones informativas?

\section{Citar este artículo}

Sánchez Illan, Carlos, y Luena, César. «Prensa, publicidad masculinidades a través de El Álbum Ibero-Americano.» Historia Y MEMORIA, n ${ }^{\circ} 22$ (2021): 119-160. DOI: https:/doi. org/10.19053/20275137.n22.2021.11138. 